\begin{tabular}{|c|c|c|c|}
\hline Anthony Stack, DO & Sandra Sheffield, DO & Karan Seegobin, MBBS & Satish Maharaj, MBBS \\
\hline $\begin{array}{l}\text { Department of Internal Medicine, } \\
\text { University of Florida College of Medicine, } \\
\text { Jacksonville, FL }\end{array}$ & $\begin{array}{l}\text { Department of Internal Medicine, } \\
\text { University of Florida College of Medicine, } \\
\text { Jacksonville, FL }\end{array}$ & $\begin{array}{l}\text { Department of Medicine, } \\
\text { Mayo Clinic, } \\
\text { Jacksonville, FL }\end{array}$ & $\begin{array}{l}\text { Department of Medicine, University } \\
\text { of Louisville School of Medicine, } \\
\text { Louisville, KY }\end{array}$ \\
\hline
\end{tabular}

\title{
Mönckeberg medial sclerosis
}

\section{A man with chronic kidney disease presents with pain and ulceration of the fingers}

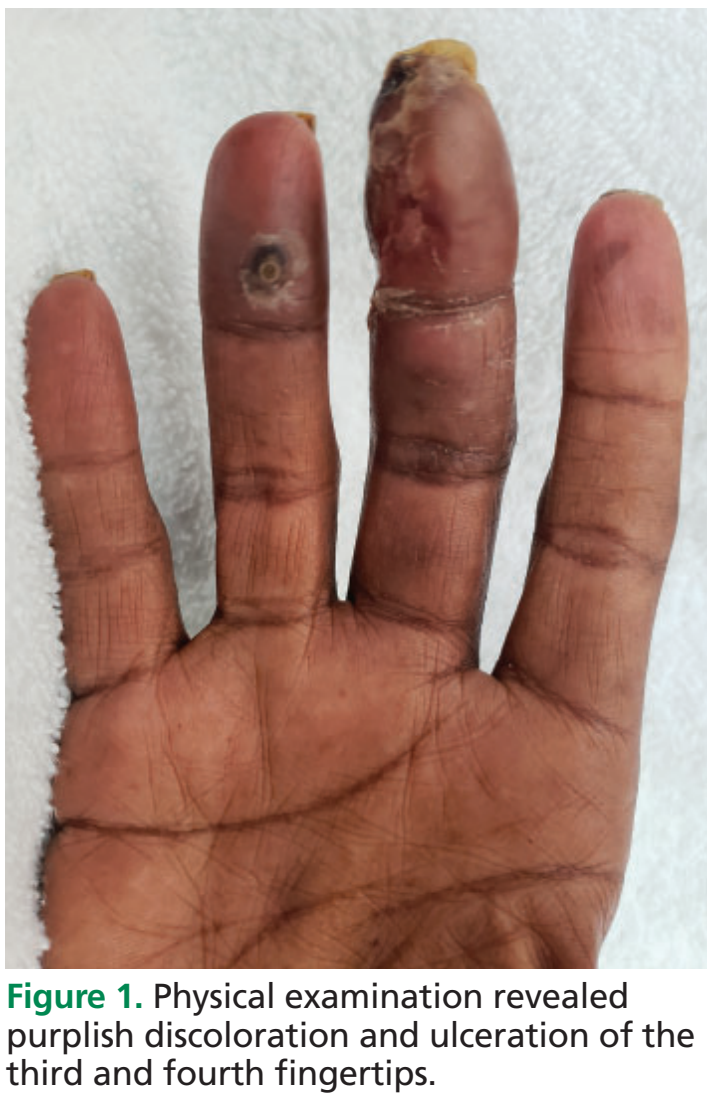

A 59-YEAR-OLD MAN presented to the emergency department with pain and ulceration of several fingers on the right hand. $\mathrm{He}$ reported no history of trauma. His medical history was significant for chronic kidney disease, coronary atherosclerosis, ischemic cardiomyopathy, and hypertension. He described antecedent pain and discoloration for 1 week, followed by blistering of the fingertips, which became ulcerated 2 days ago. He reported strict adherence to hemodialysis (performed via a tunneled catheter) and medications, including aspirin, clopidogrel, and atorvastatin.

doi:10.3949/ccjm.87a.19085
On examination, the third and fourth fingers of his right hand were purplish with distal ulcerations, worse on the tip of the middle finger (Figure 1). Palpation revealed absent radial and ulnar pulses in the right wrist and diminished radial and ulnar pulses in the left. His hands were markedly colder than his upper arms, and the right hand was colder than the left. Suspecting acute limb ischemia, we started systemic anticoagulation with heparin infusion.

Plain radiography of the hands (Figure 2A) revealed extensive vascular calcifications of the radial and ulnar arteries with no bony abnormalities. The calcifications were parallel and linear, typical of the "railroad-track" appearance that characterizes Mönckeberg medial sclerosis when the affected vessel is viewed longitudinally. Arterial Doppler ultrasonography found scattered areas of concentric calcified atherosclerotic disease. Computed tomography (CT) angiography confirmed diffuse circumferential calcification. Conventional angiography (Figure 2B) bilaterally revealed diminutive radial arteries with significantly delayed flow and occlusion of the ulnar artery bilaterally. The right distal radial artery had severe stenosis.

The vascular stenosis was not amenable to percutaneous intervention, and there were no adequate revascularization options. The right third and fourth digits and the left third digit were amputated. Medical management at discharge included a phosphate binder, vitamin D, a calcimimetic, and an aldosterone antagonist. Antiplatelet and statin therapy were continued. The frequency of hemodialysis was increased.

\section{MÖNCKEBERG MEDIAL SCLEROSIS}

The differential diagnosis for digital ischemia is broad, including arterial thromboembolism, vasoconstrictive drug use or disorders, vasculitis, infectious ulceration, Raynaud phenom- 


\section{STACK AND COLLEAGUES}

enon, and arterial stenosis. In patients with arteriovenous fistulas, steal syndrome can precipitate ischemia. In this case, there was no evidence of steal syndrome on the moreaffected side.

In general, vascular calcifications are characterized by mineral deposits in the walls of arteries, and occur as one of two types:

Intimal layer calcification occurs in atherosclerosis and is characterized by diffuse arterial involvement with late calcifications.

Medial layer calcification occurs in several diseases, of which Mönckeberg medial sclerosis is the most common. ${ }^{1}$ It typically involves discrete vascular territories with early calcification.

Mönckeberg medial sclerosis is believed to be driven by hyperphosphatemia ${ }^{2}$ and is frequently associated with diabetes and chronic kidney disease. Sclerosis tends to localize to the arteries of the extremities.

The diagnosis is supported by findings on plain radiography (Figure $2 \mathrm{~A}$ ) or B-mode ultrasonography (with distinct echogenic granules located in the abluminal layers of the arterial walls), and is confirmed with an anklebrachial index greater than $1 .{ }^{1}$ Recent research into medial layer calcifications has shown it to be an active process initiated and regulated by a variety of molecular signaling pathways. ${ }^{1}$

Compared with treatments for intimal layer calcifications, those for medial layer calcifications in general, and specifically for Mönckeberg medial sclerosis, are less well studied and effective. In patients with a documented disorder of phosphate homeostasis (typically chronic kidney disease with a mineral and bone disorder, as is the case for this patient), prevention and treatment includes phosphate binders, low-dose vitamin $\mathrm{D}$, calcimimetics, magnesium, bisphosphonates, sodium thiosul-

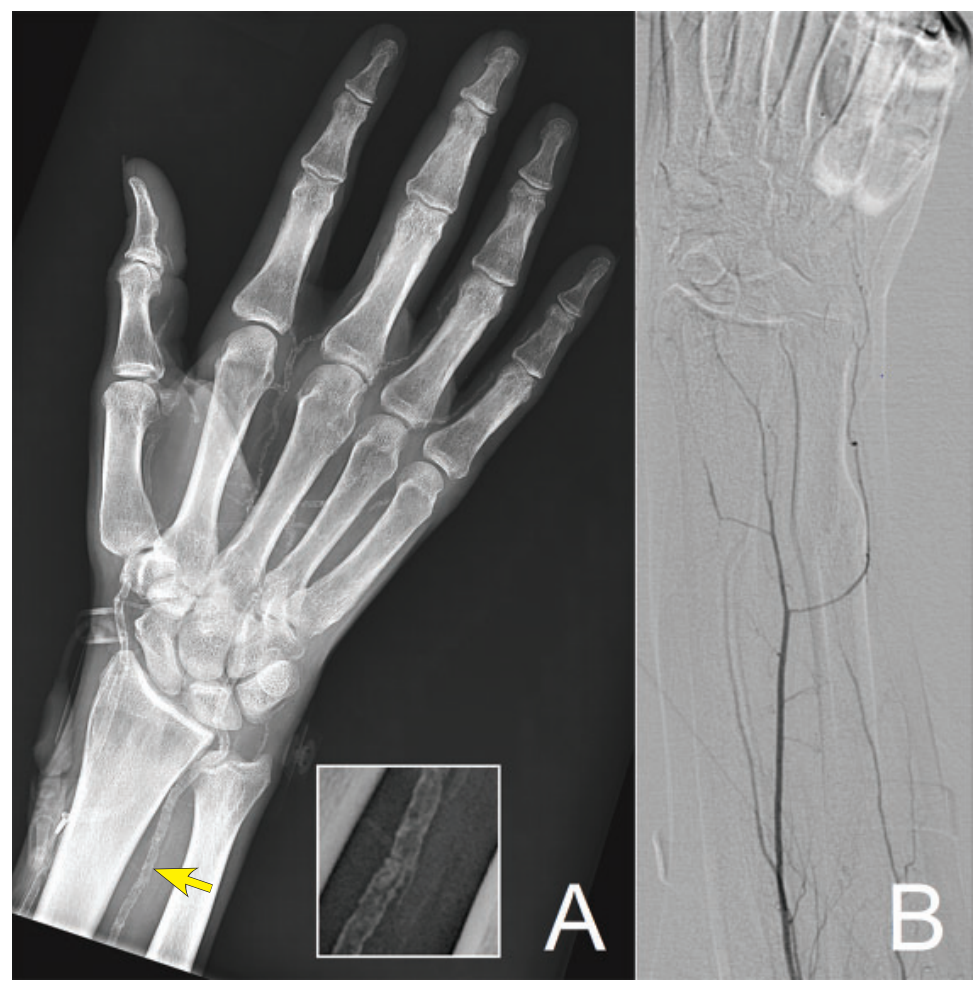

Figure 2. Plain radiography $(A)$ and conventional angiography $(B)$ demonstrated a "railroad-track" pattern (ulnar artery at arrow magnified in the inset), with severe arterial calcifications and a smooth endothelial interface, features typical for Mönckeberg medial sclerosis.

fate, and aldosterone antagonists..$^{3-5}$ In patients with skin lesions suggesting calciphylaxis, the recommended combined medical and surgical treatment includes the following:

- Lowering the calcium and phosphate concentrations

- Increasing the frequency of hemodialysis

- Giving intravenous thiosulfate

- Hyperbaric oxygen

- Wound care

- Debridement of necrotic tissue. ${ }^{6}$

\section{REFERENCES}

1. Lanzer P, Boehm M, Sorribas $\mathbf{V}$, et al. Medial vascular calcification revisited: review and perspectives. Eur Heart J 2014; 35(23):1515-1525. doi:10.1093/eurheartj/ehu163

2. Shioi A, Taniwaki H, Jono S, et al. Mönckeberg's medial sclerosis and inorganic phosphate in uremia. Am J Kidney Dis 2001; 38(4 Suppl 1):S47-S49. doi:10.1053/ajkd.2001.27396

3. O'Neill WC, Lomashvili KA. Recent progress in the treatment of vascular calcification. Kidney Int 2010; 78(12):1232-1239. doi:10.1038/ki.2010.334

4. Disthabanchong S. Lowering vascular calcification burden in chronic

kidney disease: is it possible? World J Nephrol 2013; 2(3):49-55. doi:10.5527/wjn.v2.i3.49

5. Lang F, Ritz E, Voelkl J, Alesutan I. Vascular calcification-is aldosterone a culprit? Nephrol Dial Transplant 2013; 28(5):1080-1084. doi:10.1093/ndt/gft041

6. Don BR, Chin Al. A strategy for the treatment of calcific uremic arteriolopathy (calciphylaxis) employing a combination of therapies. Clin Nephrol 2003; 59(6):463-470. doi:10.5414/cnp59463

Address: Satish Maharaj, MBBS, Department of Medicine, University of Louisville School of Medicine, 529 S Jackson St., LRC 4th Floor L-18, Louisville, KY 40207; satish.maharaj@louisville.edu 